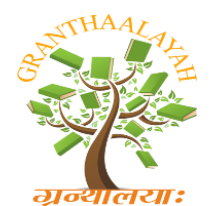

INTERNATIONAL JOURNAL OF RESEARCH -

GRANTHAALAYAH

A knowledge Repository

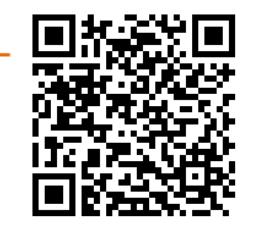

Social

\title{
A STUDY OF LANGUAGE USED FROM SELECTED DIGITAL STORYTELLING
}

\author{
Ratchadaporn Boonsing ${ }^{* 1}$, Nutprapha K. Dennis ${ }^{2}$ \\ ${ }^{* 1,2}$ English Department, Ubon Ratchathani Rajabhat University, THAILAND
}

\begin{abstract}
The purpose of this independent study was to analyze the frequency of part of speech type from a digital storytelling application. The data was selected from twenty Aesop's fables. They were categorized into eight part of speech type: noun, verb, pronoun, adjective, adverb, preposition, conjunction, and determiner. Based on the twenty stories, there were a total of 1,341 words. The results show that, first, there were 313 or $23.34 \%$ categorized as verbs, second, 263 nouns or $19.61 \%$, third, 183 pronouns or 13.65\%, forth, 174 determiners or $12.98 \%$, fifth, 120 prepositions or $8.95 \%$, sixth, 115 conjunctions or $8.58 \%$, seventh, adverbs or $6.82 \%$, and, eighth, 81 adjectives or $6.04 \%$. Therefore, the most frequent part of speech type used in the digital storytelling application was verb with 313 words at the percentage of 23.34\%. And the least frequently used type in storytelling was the adjective with 81 words at the percentage of $6.04 \%$. The results show that "verb" was the most frequently used in the storytelling. Verbs were in every sentence of fables. The next most frequently used noun, pronoun, determiner, preposition, conjunction, adverb and adjective, respectively. The results of the study can help students learning vocabulary and their functions more conveniently.
\end{abstract}

Keywords:

Vocabulary Learning, Storytelling, Aesop's fable, Part of speech.

Cite This Article: Ratchadaporn Boonsing, and Nutprapha K. Dennis, "A STUDY OF LANGUAGE USED FROM SELECTED DIGITAL STORYTELLING" International Journal of Research - Granthaalayah, Vol. 4, No. 3 (2016): 27-32.

\section{INTRODUCTION}

English is generally accepted as a universal language; therefore, it is used in many areas, such as sensible, rule, medicine, economics, as well as education. Thus, it is necessary that learners study English as a language that is used for communication all over the world. Learning English is supported in many countries, including Thailand. In Thailand, English language has been incorporated in the curriculum as a core subject since 1896. However, in the 1996 curriculum, some changes have been made so that English has become an optional subject. According to the current curriculum, the goal of English instruction is to develop learners' communicative capability. 
Vocabulary is a main section of language learning and has been the object of several studies, each of which has its own contribution to the field. Laufer (1997), mentions that vocabulary learning is the heart of language learning and language use. Coady (1997) stated that second language vocabulary acquisition has become an increasingly interesting topic of discussion for researchers, teachers, curriculum designers, theorists, and others involved in second language learning. Vocabulary is important so that the learner understands the correct meaning of the words so that they can choose appropriate words for a specific context. The higher the amount of vocabulary of a second language learner, the better the learner will speak and write the language. Learning the vocabulary correctly is important for second language learners as it will increase their language skill, e.g. speaking and writing correctly and allowing them to express ideas and opinions both in the classroom and outside. The second language learners need to acquire a sizable basic vocabulary through repeated exposure.

Learning a second language involves the management of four main skills; speaking, writing, listening and reading, which lead to effective communication. An essential factor is the amount of vocabulary one possesses as vocabulary forms the biggest part of the meaning of any language. Vocabulary, however, is the biggest problem for most learners. In view of this, vocabulary acquisition is currently receiving attention in second language pedagogy and research. But it is still an argumentative issue how learners acquire vocabulary effectively and efficiently or how it can best be taught.

The lesson of multimedia can help to solve the problem of teachers who lack technique and skills in teaching. In other words, there is a repetitious, monotonous, and tedious teaching and learning process and teachers do not put the instrument in their teaching. Teachers have to apply the new technology in teaching because the instructional media will help the students become interested, enjoy the learning and it is advantages for teacher. Both students and teachers are able to learn together. In addition, the modern instructional media is also reforming education so that it makes the present study focus and try to create an educational instrument to enhance the efficiency of learning and teaching. In this research, the researcher used electronic storytelling books that are part of multimedia in language learning.

For this reason, the researcher is interested in the study of English vocabulary learning by using multimedia for primary students that will make the students learn foreign language and understand meaning of the story as well. It is also getting the ethics and morals which are in the storytelling.

Storytelling is a term used to describe the oral telling of stories to groups of children in libraries and other institutions (Carpenter \& Mari, 1984). It is an art form through which a storyteller projects mental and emotional images to an audience using the spoken word, including gestures and sign language to carefully match story content with audience needs and environment. The story resources reflect all literatures and cultures, fiction and nonfiction and serve recreational, folkloric, entertainment, therapeutic purposes and also historical and educational purposes (Yarnspinner, 1980:20-31).

Purpose of the Study: The purpose of this study was to analyze the frequency of each type in part of speech from storytelling by using multimedia for primary students. 
Significance of the Study: The significances of this study are 1) this study may be useful for students who would like to learn English vocabulary by using storytelling 2) This study may be a guide for English teachers who would like to teach vocabulary by using storytelling. 3) This study might be beneficial for interested people who would like to learn English vocabulary by using storytelling.

Scope of the Study: This study covers only twenty Aesop's fables. The Aesop's fables were selected and used with primary students for finding the frequency of part of speech: noun, verb, pronoun, adjective, adverb, preposition, conjunction, and determiner.

Limitations of the Study: The limitations of this study are 1) there are many Aesop's fables for primary students. Twenty Aesop's fables were used in the study 2) In the part of speech, there are many words used in the sentence structures that were occurred in the collected data of the study. Then, the frequency of each of type in part of speech: noun, verb, pronoun, adjective, adverb, preposition, conjunction, and determiner are counted and analyzed.

\section{MATERIALS AND METHODS}

Setting: The data in this study was based on twenty Aesop's fables from MIS Publishing House. In one set, there are ten stories in a book and a DVD. The study used twenty stories for analyzing verb focuses on regular verbs and irregular verbs.

Research Instruments and Materials: The research instruments used in this study was twenty Aesop's fables from bilingual fable multimedia as follows: "The Goose with the Golden Eggs, The Mother Crab and Her Son, The Sick Stag, The Farmer and His Sons, The Ass and His Purchaser, The Quack Frog, The Peacock and the Crane, The Snake and the File, The Fox and the Mask, The Seller of Image, The Hare and the Tortoise, The Fox and the Grapes, The Widow and Her Hen, The Hawk and The Nightingale, The Dogs and the Cowhides, The Eagle and the Tortoise in the Air, The Camel and the Arab, The Crow and the Serpent, The Wolf and the Lamb, The Crow and Mercury".

Data collection and data analysis: The data collected through the following procedures; 1) the Aesop's fables were selected by researcher. There are twenty stories to analyze 2) classified the vocabularies that are in Aesop's fables to regular verbs and irregular verbs 3) frequency of group of regular verbs and irregular verbs were analyzed and described 4) Summarized and discussed the research in the final. The data analysis was the frequency kind of verb of regular verbs and irregular verbs that were described by descriptive statistics to report the percentage in the study. The results of the data collection are shown in the next chapter.

\section{RESULTS AND DISCUSSIONS}

Table 1: Summary of the amount of vocabularies and percentages of part of speech used in twenty Aesop's fables

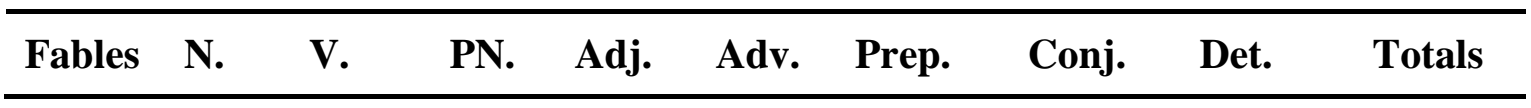




\begin{tabular}{llllllllll}
\hline $\mathbf{2 0}$ & 263 & 313 & 183 & 81 & 92 & 120 & 115 & 174 & 1341 \\
$\mathbf{1 0 0 \%}$ & $\begin{array}{l}19.6 \\
1\end{array}$ & 23.34 & $\begin{array}{l}13.6 \\
5\end{array}$ & 6.04 & 6.86 & 8.95 & 8.58 & 12.98 & 100.00 \\
\hline
\end{tabular}

Table 1 presents the amount of vocabularies and percentages of part of speech from twenty example of storytelling by using Aesop's fables. In the storytelling based on twenty stories that used 313 words that were Verbs at the percentage of $23.34 \%$. The second, Nouns had a count of 263 words at the percentage of $19.61 \%$. The third, Pronouns accounted for 183 words at the percentage of $13.65 \%$. The fourth, Determiner totaled 174 words at the percentage of $12.98 \%$. The fifth, Preposition was used 120 times at a percentage of $8.95 \%$. The sixth, Conjunction was used 115 times at a percentage of $8.58 \%$. The seventh, 92 words were identifies as Adverbs at a percentage of $6.82 \%$. And the lastly, words that are Adjectives were used a total of 81 times at a percentage of $6.04 \%$. In conclusion, the most used type of part of speech in storytelling was Verb with 313 words at the percentage of $23.34 \%$. The least used type of part of speech in storytelling was Adjective with 81 words at the percentage of $6.04 \%$.

Discussions: In the analysis of the study, we find that there were some interesting point should be discussed. In this study, the eight types of part of speech that were analyzed separately were noun, verb, pronoun, adjective, adverb, preposition, conjunction, and determiner. The vocabularies in twenty Aesop's fables were categorized into part of speech, the results show that the amount of vocabularies most frequently used "verb" in the storytelling. Verbs were in every sentence of fables. The Next most frequently used Noun, Pronoun, Determiner, Preposition, Conjunction, Adverb and Adjective, respectively. They can make the students easy to learn vocabulary and function of vocabulary as well. According to Ellis \& Brewster (1991) mentioned that vocabulary in stories is presented in a vivid and clear context and the illustrations help to convey meaning. They also stated that both the meaning and the amusing situations can make the vocabulary easy to remember. Guessing from context would encourage students to take risks to guess the meaning of words they do not know. It will help students build up self-confidence so that they can work out the meaning of words when they are on their own. Many clues students can use to establish meaning for themselves: pictures in the storybooks, spelling or sound in the mother tongue and general knowledge. Shepard (1996:100-120) mentioned that storytelling gives expression to their emotional needs, allows their imaginations to soar and gives them opportunity to share in the experiences that have shaped storytellers' world. In addition, storytelling may help the students memorize the vocabulary and practice English. As Puangwipart (2011:75) studied "the effects of learning achievement and retention of English vocabulary by using English storytelling an electronic book for Pratomsuksa five". Storytelling e-book was a media that encourage individualized instruction of learners. The learners can always learn and review the lesson that they want. He gave the vocabulary test to the learners. The effects of learning achievement show the score after learning vocabulary were higher than the previous learning vocabulary by using storytelling an electronic book. And the results of satisfaction questionnaires of learning English vocabulary by using English storytelling an electronic book were very good level. 


\section{CONCLUSIONS \& RECOMMENDATIONS}

In this study, the purpose was to analyze the frequency of each part of speech type from storytelling by using multimedia for primary students. The data in this study was based on twenty Aesop's fables from MIS Publishing House. In one set, there is a ten-story book and a DVD. The study used twenty stories for analyzing parts of speech. This study is a survey research. The data collection was selected from MIS Publishing House that was bilingual Aesop's fable with a DVD. The frequency of these parts of speech was analyzed: noun, verb, pronoun, adjective, adverb, preposition, conjunction, and determiner. The production of this study indicated the frequency and the percentage of each part of speech type. The finding of this study could be an instrument in teaching and learning English vocabulary. The frequency and percentage showed the amount of each part of speech type for use in storytelling.

The amount of vocabularies and percentages of part of speech used in twenty Aesop's fables. They used vocabulary totaling 1,342 words and categorized them to each part of speech type. The top part of speech type that was used in storytelling was the Verb with a total of 313 words at the percentage of $23.34 \%$. The second most frequently used type was the Noun with a total of 263 words at the percentage of $19.61 \%$. The third most frequently used type was the Pronoun with a total of 183 words at the percentage of $13.65 \%$. The fourth most frequently used type was the Determiner with a total of 174 words at the percentage of $12.98 \%$. The fifth most frequently used type was the Preposition with a total of 120 words at the percentage of $8.95 \%$. The sixth most frequently used type was the Conjunction with a total of 115 words at the percentage of $8.58 \%$. The seventh most frequently used type was the Adverb with a total of 92 words at the percentage of $6.86 \%$. And the least frequently used type was the Adjective with a total of 81 words at the percentage of $6.04 \%$. In conclusion, the most frequently used part of speech in storytelling was the Verb with a total of 313 words at the percentage of $23.34 \%$. And the least frequently used type in storytelling was the Adjective with only 81 words at the percentage of $6.04 \%$.

Recommendations: Studying the analysis from the frequency of parts of speech from storytelling, the finding of this study can be beneficial to learners. The implications of this study are important:

1. This study can be used as a guideline in analysis of English vocabulary or other languages.

2. The study is useful for the teachers to apply towards teaching English vocabulary which enhances students' interest and motive.

3. The finding of this study might help the learners get more knowledge about English vocabulary and categorize into each part of speech type.

4. The scope of study could be broadened to include a sampling of storytelling because there are many stories and publishing houses.

5. Other materials such as movies, songs, newspapers, advertisements etc. should be considered to study as well.

6. The learners who would like to learn English vocabulary can utilize this case study as a basic knowledge to understanding the function in part of speech in other materials. 
7. English instructors, teachers, parents and guardians who would like to teach English vocabulary by using storytelling can easily use this case study as their teaching resource to enhance learners' educational outcome intensively.

8. Further studies should include more examples of storytelling.

9. There are various strategies to learning English vocabulary, in the future the researcher could study other aspects.

10. A further study should select the vocabulary from many different sources to compare the function of vocabulary used for other source.

\section{ACKNOWLEDGEMENTS}

This case study would not have been possible without the dedication and good counsel of a great many people. First of all, I would like to express my sincere gratitude to my advisors, Nutprapha Kongphet Dennis, Ph.D. for her excellent supervision, valuable guidance, intellectual support and encouragement throughout this study. At the same time, I wish to express my appreciation to all of the instructors of the Faculty of Humanities and Social Science of Ubon Ratchathani Rajabhat University who have contributed to helping me throughout the learning process. I also express a special thanks to all of my friends in Master of Arts in English 10 at Ubon Ratchathani Rajabhat University for their encouragement, support and love. Finally, I would like to express my personal thanks to my beloved family especially my parents who give me their love, encouraged and cheer me up throughout my study.

\section{REFERENCES}

[1] Coady, J. L2 vocabulary Acquisition through extensive reading. Cambridge: Cambridge University Press. n.p. 1997.

[2] Ellis, G. \& Brewster, J. The Storytelling Handbook for Primary Teachers. Penguin Book Ltd. 1991:75.

[3] Laufer, B. The Lexical Plight in Second Language Reading. Cambridge: Cambridge University. n.p., 1997.

[4] Puangwipart, D., Affects of Learning Achevement and Retention of English Vocabulary by Using English Storytelling Electronic Book for Pratomsuksa Five. Master of Arts Thesis. Silpakorn University, 2011:75.

[5] Shepard, A. Playing the language game. Bugkingham: Open University Press, 1996:100120

[6] Yarnspinner, S. Jonesborough Tenn: National Association for the Preservation and Perpetuation of Storytelling. (Serial Online), 5 (1980): 20-31. 